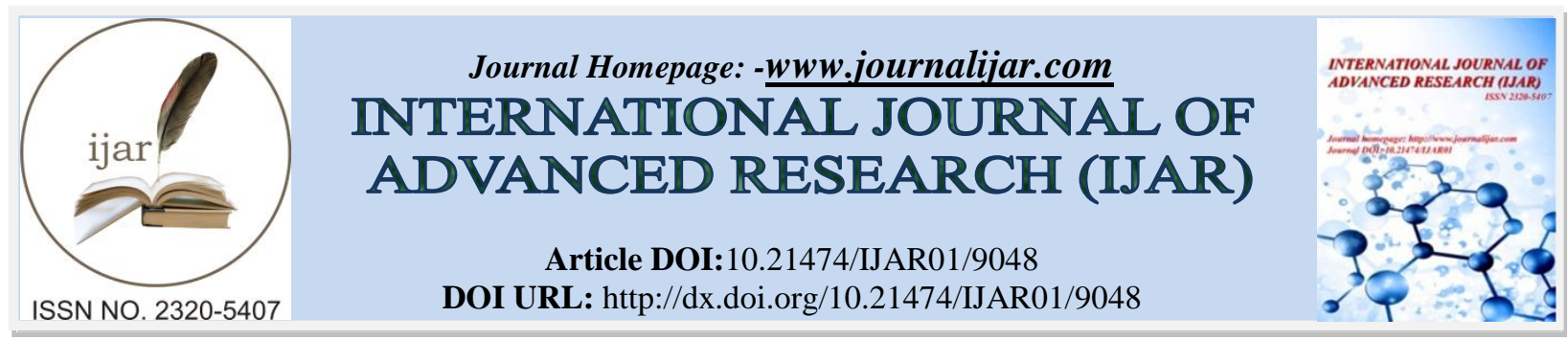

RESEARCH ARTICLE

\title{
SECONDARY AMENORRHEA WITH HYPOGONADOTROPIC HYPOGONADISM ASSOCIATED TO A CEREBELLAR ATAXIA: DIAGNOSIS CONTINGENCIES.
}

\author{
Maryam Soussou, Ghizlane El Mghari And Nawal El Ansari. \\ Department of Endocrinology Diabetology and Metabolic Diseases,FMPM, Cadi Ayad University, CHU Mohamed \\ VI, Marrakech, Morocco.
}

\section{Manuscript Info}

Manuscript History

Received: 12 March 2019

Final Accepted: 14 April 2019

Published: May 2019

Key words:-

secondary amenorrhea, cerebellar syndrome, hypergonadtrophic, hypogonadism, ataxia, nystagmus, retinal atrophy.

\section{Abstract}

The association between hypogonadism and cerebellar ataxia was first recognized and described as a distinct, rare, autosomal recessive syndrome by Gordon Holmes in 1907.Both hypo and hypergonadotrophic forms were descriebed. We report the case of 29year-old women with secondary amenorrhea and cerebral ataxia and was found to have hypergonadotrophic hypogonadism with cerebellar atrophy which is a rare association. She also had a nystagmus, sensorial neurological syndrome, retinal atrophia, and ligamentous hyperlaxity.Other syndromes appears to be also a diagnosis eventuality, such as for Boucher-Neuhauser syndrome The association of spinocerebellar ataxia, hypogonadotropic hypogonadism, and chorioretinal dystrophy and Perrault syndrome that the association of hypergonadotropic hypogonadism in females and sensorineural hearing loss that is associated also with neurological symptoms evolving or not ataxia. There is little understanding of the pathophysiology mechanism of this association, many theories are proposed in order to make therapeutic advances, specially that heridatarian ataxia have a very bad prognosis, genetic therapies may be revolutioning the therapeutic arsenal.

Copy Right, IJAR, 2019,. All rights reserved.

\section{Introduction:}

The association between hypogonadism and cerebellar ataxia was first recognized and described as a distinct, rare, autosomal recessive syndrome by Gordon Holmes in 1907[1]. Initially, most cases reported a hypogonadotrophic hypogonadism due to a defect in the production or release of gonadotropins by the pituitary gland. But since, a hypergonadotropic forms were also reported showing that endocrinological heterogeneity exist. Genetic studies revolutionned the understanding of these pathology, unfortunately, because of their high cost, these studies are not available in all countries. Here, we report the case of a 29-year-old women with secondary amenorrhea and cerebral ataxia and was found to have hypergonadotrophic hypogonadism with cerebellar atrophy which is a rare association.

\section{Case presentation:}

29-year-old women, born out of a first degree consanguineous parentage, referred to our unit for secondary amenorrhea. She has reported a history of progressive balance disorder of 14 years duration, diagnosed as a cerebellar ataxia treated by vitamin therapy (E). She had a history of breast nodule surgery whose anatomopathlogic

Corresponding Author:-Maryam Soussou. 
study revealed a neurofibroma. Her brother had a Von Recklinghausen disease. There was no family history of ataxia, ovarian insufficiency or infertility. Her menarche was at the age of 14 years, her spaniomenorrhea started from 5 years at the age of 24 and she presented a secondary amenorrhea 3 years from examination.

Clinical examination showed a patient with a normal intelligence, normal height and weight. Neurological examination showed a normal speech, unsteady gait with tendency to fall. She was unable to walk alone. Finger-tonose test revealed dysmetria and tremor on both sides. She had a peripheral neurogenic syndrome with abolished osteo-tendinous reflexes; the muscle strength was $5 / 5$ with. Gaze-evoked vertical nystagmus in both eyes. Cranial nerves were normal. Ligamentous hyper laxity was found at both hand articulations (wrist and fingers).

Brain MRI revealed verminal and cerebellar atrophy (Figure 1). Electromyogram (EMG) showing pure sensory neuropathy of the 4 limb. Serum Vitamin E was low $4,7 \mathrm{mg} / 1(6,8-15)$. Apo lipoproteins were normal. Endocrinological assessment showed raised serum levels of follicle stimulating hormone: $162(1.2-9 \mathrm{mIU} / \mathrm{ml})$, luteinizing hormone: $69(0.6-14 \mathrm{mIU} / \mathrm{ml})$ and low estradiol: $8(60-300 \mathrm{pg} / \mathrm{ml}) ; \mathrm{ml}$ indicating a hypergonadotrophic type of hypogonadism, anti mullerian hormone: $0,1 \mathrm{ng} /$. Deficiency of Vitamin D: $7.9 \mathrm{ng} / \mathrm{ml}$ was also objectified. Thyroid function, prolactinemia, and cortisolemia were normal. Pelvic ultrasound showed a normal sized uterus of homogeneous structure of regular outline, ovaries without abnormality. Ophthalmological examination showed a good macular reflection with minimal chorio-retinal atrophy. Hemogram, renal, hepatic exams were normal. Pure tone audiogram showed normal hearing. Electrocardiogram and echocardiography were normal. The Karyotype was normal (46 XX). After substitution of vitamin D, the osteo-densitometry done was normal. Echo-mammography: revealing an ACR3-classified breast lesion measuring $3 \mathrm{~cm} * 4 \mathrm{~cm}$. We planned to put the patient on hormone replacement therapy after the management of the voluminous breast nodule. For her ataxia, she was diagnosed as a Frideriech ataxia and was treated by Vitamin E therapy, and physiotherapy and Co enzyme Q 10 analog, which was unavailable in the country so the patient couldn't be observant to this treatment.

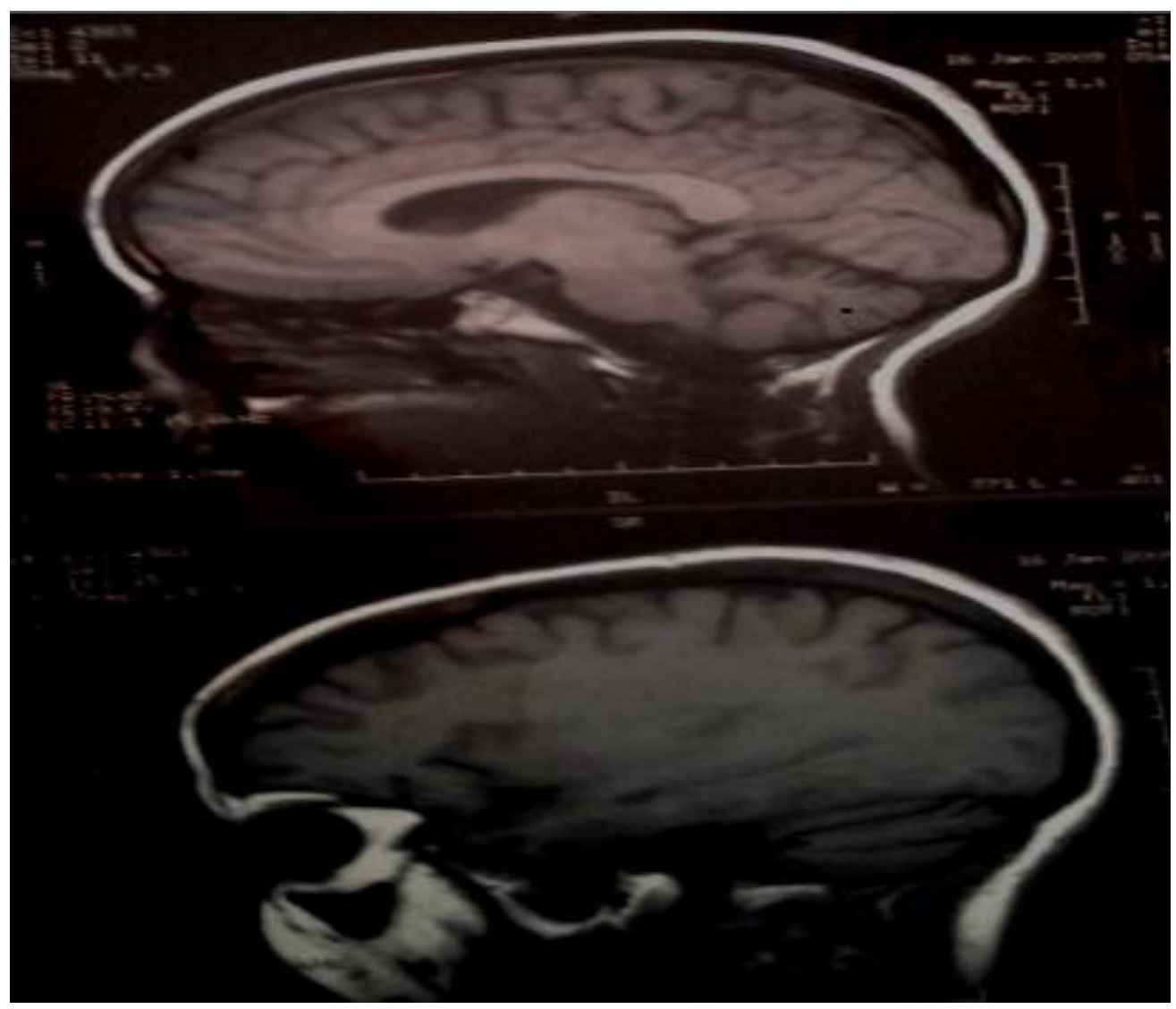

Figure 1:-Magnetic resonance imaging Brain: cerebellar atrophy 


\section{Discussion:}

This case illustrates a syndrome characterized by the association of cerebellar ataxia, secondary amenorrhea, and hypergonadotropic hypogonadism. The main and first known syndrome that gathers ataxia and hypogonadism is the autosomic recessive Gordon Holmes syndrome. Both hyper and hypogonadotropic forms were reported. There is little understanding of the pathophysiology mechanism of this association. However, it has been reported that improved detection methods revealed the presence of estrogen receptors in the cerebellum, explaining the estrogen responsiveness of the cerebellum [2-3].Estrogen affects cerebellar functions by enhancing Purkinje cell responsiveness to glutamate, thus augmenting glutamatergic neurotransmission (4-5].Potential for estrogen replacement therapy in the treatment of cerebellar ataxia was suggested in studies of an animal model of cerebellar ataxia [6] and estrogen has been shown to have beneficial effects in the treatment of Friedreich ataxia [7].In this case the chronology of the appearance of ataxia 10 years before hypogonadism, does not support this physiopathogeny theory . Even though, estrogenic substitutive therapy will be proposed to our patient after the management of the mammary nodule, in order to substitute the gonadal axis, prevent her from osteoporosis, and eventually for its benefits on the ataxia. Specially as we ruled out the ataxia with Fridereich ataxia ,the most common hereditary ataxia .It is an autosomic recessive syndrome due in more than $96 \%$ of cases to an expansion of the repetition of GAA triplets inintron 1 of the FXN gene, causing the loss of function of a protein called frataxin [8,9,10,11,12]. In nearly $4 \%$ of cases, there is, in addition to expansion, a punctuel mutation $[12,12]$. These mutations lead to a loss of function of frataxin, a mitochondrial ubiquitous protein implicated notably in the biosynthesis of iron / sulfur core proteins and iron homeostasis in mitochondria [14, 15].The associated abnormalities are: hypertrophic cardiomyopathy (in about $60 \%$ of cases) usually revealed by echocardiography, diabetes (in almost $30 \%$ of cases) while nystagmus is not a common sign of the pathology), and less has optic atrophy or hollow feet. Patients gradually lose walking in about eight years [8]. The treatment is based jointly on speech therapy, physiotherapy and the administration of a coenzyme Q10 analog [8, 16, and 17]. Ataxia due to vitamin E deficiency is the second most common inherited ataxia after Fredereich ataxia in North Africa [8]. The assessment shows a very low blood level of vitamin $\mathrm{E}(<2.5 \mathrm{mg} / \mathrm{L}$ and very often $<1 \mathrm{mg} / \mathrm{L}$ for a standard between 6 and $15 \mathrm{mg} / \mathrm{L})$, the diagnosis confirmed by the identification of mutations in the TTPA gene, which encodes the $\alpha$-tocopherol transfer protein [8, $18,19,20]$ involved in the transfer of Vitamin E to VLDL. Vitamin E in a daily and chronic way would slow the progression of the disease or even reduce some neurological symptoms. In this case the level vitamin $\mathrm{E}$ was low but does not concord with the definition; however the vitamin E supplementation were indicated, because of its possible benefits aforesaid.

The association of spinocerebellar ataxia, hypogonadotropic hypogonadism, and chorioretinal dystrophy as an autonomous single-gene disorder was described by Boucher and Gibberd in 1969 and Neuhausser and Opitz in 1975 and is designated as Boucher-Neuhauser syndrome [21].Our patient presented a minimal chorio retinal dystrophy, and hypogonadism in our case is hypergonadotropic type.

The association of hypergonadotropic hypogonadism in females and sensorineural hearing loss in females and males was first described in 1951 as Perrault syndrome. This is also genetic syndrome inherited in an autosomal recessive manner. Affected females have streak gonads in place of their ovaries with primary amenorrhea. Some patients also have neurological manifestations in the form of mental subnormality and cerebellar involvement. Amor et al. reviewed patients with the rare association of ataxia and hypergonadotropic hypogonadism (AAH) and documented 15 cases and suggested to use a separate category for this phenotype [22].Our patient didn't have a hearing loss, but it might appear eventually.

As the physiopathology of the association of hypogonadim and ataxia in all these syndromes is unknown, the question remains whether one gene is implicated in all the different clinical forms of each one of these autosomal recessive syndromes or if there are at least two different genes responsible for two different clinical entities. It is more reasonable, as suggested Sarikaya E and al while discussing a variant of Perrault syndrome, to ascribe this association as a clinical entity with a different, yet not fully understood, pathogenesis mechanism in which the involvement of different genotypes may lead to the same or similar phenotypic manifestations. He explained that the association of ataxia hypergonadotropic hypogonadism and hearing loss could be caused by both a malfunction of the mitochondria and of myelination. Depending on the genes involved, it may have autosomal recessive or mitochondrial inheritance. The inter familial variation of both the severity of hearing loss and the onset of amenorrhea, and neurological symptoms in individuals may turn out to be due to environmental or genetic factors influencing the effect of mutations [23].Many treatment are proposed in the bases of the eventual physiopathogeny theories of this association. As it still hypothetical, trials did not exceed the animal experiences stages. 
Ataxia-telangiectasia-like disorder (ATLD) is a very rare disease with autosomal recessive inheritance, first reported as a milder form of ataxia-telangiectasia (AT) [Hernandez et al., 1993]. Advances in genetics have revealed that ATLD is caused by mutations in the MRE11 gene, which is involved in DNA double-strand break repair (DSBR) together with ATM, the causative gene in AT [24,25]. Patients with ATLD show progressive cerebellar ataxia, abnormal eye movement, and increased cellular radiosensitivity, all of which are also observed in AT. However, in contrast to AT, ATLD patients exhibit no extra-neurological features, such as telangiectasia, reduced immunoglobulin levels, or raised alpha fetoprotein. The lack of such key clinical features makes it difficult to distinguish this condition from other cerebellar ataxias; hence correct diagnosis is delayed in the majority of cases. Due to the rarity of ATLD, the gonadal status of patients has not been well described. In the case of AT, some female patients have been reported to show primary ovarian failure [26]. Yoshida $\mathrm{T}$ et al reported a case of a patient presenting with previously undescribed features; hypergonadotropic hypogonadism and hyper segmented neutrophils. Genetically, a novel missense mutation (c.140C >T) was detected in the MRE11 gene, Western blot assay demonstrated total loss of MRE11 and reduction of ATM-dependent phosphorylation; thus, the diagnosis of ATLD was established. So it was suggested considering ATLD, when assessing patients with ataxia of unknown cause[27].

The weakness of our case was that we could not perform appropriate genetic testing in our patient as well as her first-degree relatives.

\section{Conclusion:}

All reported cases of hypogonadism associated with cerebellar ataxia reveals a great heterogeneity in the causative pathogenic mechanisms. It is more reasonable to ascribe this association as a clinical entity with different genotypes involved, which may lead to the same or similar phenotypic manifestations. Our patient came from a consanguineous marriage; her parents were healthy, suggesting an autosomal recessive inherited syndrome explaining her symptoms. From more than a hundred years Gordon Holmes gave his name to a syndrome associating hypogonadism and ataxia that he had discovered. Many other syndromes came after that, describing this same association with different other abnormalities. We actually, rely on the clinical studies and hope that genetic advances will help to understand more these syndromes in order to improve these inefficient therapeutic available now for these syndromic patients.

\section{Conflicts of Interest}

The author(s) declare(s) that there is no conflict of interest regarding the publication of this paper.

\section{References:}

1. Holmes GA. Form of familial degeneration of the cerebellum. Brain. 1908; 30(4): 466-489.

2. Price Jr RH, Handa RJ (2000). Expression of estrogen receptor-beta protein and mRNA in the cerebellum of the rat. Neurosci Lett 288: 115-118.

3. Mitra SW, Hoskin E, Yudkovitz J et al. (2003). Immunolocalization of estrogen receptor beta in the mouse brain: comparison with estrogen receptor alpha. Endocrinology 144: 2055-2067.

4. Smith SS, Waterhouse BD, Woodward DJ (1988). Locally applied estrogens potentiate glutamate-evoked excitationof cerebellar Purkinje cells. Brain Res 475:272-282.

5. Andreescu CE, Milojkovic BA, Haasdijk ED et al. (2007).Estradiol improves cerebellar memory formation byactivating estrogen receptor beta. J Neurosci 27:10832-10839.

6. Sierra A, Azcoitia I, Garcia-Segura L (2003). Endogenous estrogen formation is neuroprotective in model of cerebellar ataxia. Endocrine 21: 43-45.

7. Richardson TE, Kelly HN, Yu AE et al. (2013). Therapeutic strategies in Friedreich's ataxia. Brain Res 1514: 91-97.

8. M. Anheim. Les ataxies cérébelleuses autosomiques récessives. Pratique Neurologique FMC 2011; $2: 237-249$.

9. Wedding I, Kroken M, Pilar HenriksenS, Selme K et al. Friedreich ataxia in Norway - an epidemiological, molecular and clinical study. Orphanet Journal of Rare Diseases (2015) 10:108;1-17

10. Reetz K,Dogan M, Costa A, Dafotakis M, et al .Biological and clinical characteristics of the European Friedreich's Ataxia Consortium for Translational Studies (EFACTS) cohort: a cross-sectional analysis of baseline data. Lancet

11. Kim JS,Whan Cho J, et al. Hereditary Cerebellar Ataxias: A Korean Perspective, J Mov Disord 2015;8(2):6775. 
12. Campuzano.V,Monterminé et al. Friedreich ataxia ,autosoaml recessive disease caused by intronic GAA tripelet repeat expansion. Science (New York)1996,271(5224).

13. Cossee M, Durr A, Schmitt M, Dahl N, Trouillas P, Allinson P et al. Friedreich's ataxia: point mutations and clinical presentation of compound heterozygotes. Annals of neurology 1999;45:200-6.

14. Marioti, Solari et al. Idebenone treatement in Friedreich patients. neurology,2003.60(10:1676-9);

15. Rustin P, Vonklest, Retzow et al, Effect of idebenone on cardiomyopathie in Friedreich ataxia,a preliminary study. Lancet 1998,354(9177):477-9.

16. El Euch-Fayache G, Bouhlal Y, Amouri R, Feki M, et al. Molecular, clinical and peripheral neuropathy study of Tunisian patients with ataxia with vitamin E deficiency. Brain 2014: 137; 402-410.

17. Koenig M, Mandel JL. Deciphering the cause of Friedreich ataxia. Curr Opin Neurobiol 1997;7:689-94.

18. Rotig A, de Lonlay P, Chretien D, Foury F, Koenig M, Sidi D, et al. Aconitase and mitochondrial iron-sulphur protein deficiency in Friedreich ataxia. Nature genetics 1997;17:215-7.

19. Benhamida C,Doerflinger et al. Localization of friedreich ataxia phenotype with selective vitamine E deficiency to chromosome $8 \mathrm{q}$ by homozygoty. maping- nat genet1993j5(2):195-200.

20. Benomar A, Yahyaoui M, Meggouh F,et al. Clinical comparison between AVED patients with 744 del A mutation and Friedreich ataxia with GAA expansion in 15 Moroccan families ournal of the Neurological Sciences 198 (2002) 25-29

21. Amor DJ, Delatycki MB, Gardner RJ, Storey E. New variant of familial cerebellar ataxia with hypergonadotropic hypogonadism and sensorineural deafness. Am J Med Genet. 2001; 99(1): 29-33.

22. Georgopoulos NA, Papapetropoulos S, Chroni E, Papadeas ES, Dimopoulos PA, Kyriazopoulout V, Davis Cerebellar ataxia and hypergonadotropic hypogonadism associated with familial sensorineural hearing loss. Gynecol Endocrinol. 2004; 19(2): 105-110.

23. Sarikaya E,1 Ensert CG,2 Gulerman H,Hyperdonadotropic hypogonadism, progressive early onset spinocerebellar ataxia, and late onset senrineural hearing loss case report and literature review, BJMG 14/2 (2011) 77-88 10.2478/v10034-011-0050-z

24. Savitsky K, Bar-Shira A, Gilad S, Rotman G, Ziv Y, Vanagaite L, Tagle DA, Smith S, Uziel T, Sfez S, Ashkenazi M, Pecker I, Frydman M, Harnik R, Patanjali SR, Simmons A, Clines GA, Sartiel A, Gatti RA, Chessa L, Sanal O, Lavin MF, Jaspers NG, Taylor AM, Arlett CF, Miki T, Weissman SM, Lovett M, Collins FS, Shiloh Y. 1995. A single ataxia telangiectasia gene

25. with a product similar to PI-3 kinase. Science 268:1749-1753.

26. Stewart GS, Maser RS, Stankovic T, Bressan DA, Kaplan MI, Jaspers NGJ, Raams A, Byrd PJ, Petrini JHJ, Taylor AMR. 1999. The DNA doublestrand break repair gene hMRE11 is mutated in individuals with an ataxiatelangiectasia-like disorder. Cell 99:577-587.

27. Zadik Z, Levin S, Prager-Lewin R, Laron Z. 1978. Gonadal dysfunction in patients with ataxia telangiectasia. Acta Paediatr Scand 67: 477-479.

28. Yoshida T, Awaya T, Shibata M, Kato T, Numabe H, Kobayashi J, Komatsu K, Heike T. 2014. Hypergonadotropic hypogonadism and hypersegmented neutrophils in a patient with ataxia-telangiectasia-like disorder: Potential diagnostic clues? Am J Med Genet Part A 164A:1830-1834. 